\title{
Chemical Fixation of Mesh in Repair of Inguinal Hernia: Long Term Follow Up
}

\author{
Ahmed Abd El Aal Sultan* \\ Assistant professor of general surgery, Faculty of medicine, Al-Azhar university, Egypt \\ *Corresponding author: Ahmed Abd El Aal Sultan, Assistant professor of general surgery, Faculty of medicine, Al-Azhar \\ university, Egypt
}

\begin{tabular}{|c|c|}
\hline ARTICLE INFO & ABSTRACT \\
\hline Received: 幽 February 05, 2021 & $\begin{array}{l}\text { Background: Repair of inguinal hernia is the most widely disseminated operation } \\
\text { in general surgery, because of high incidence of occurrence and high incidence of }\end{array}$ \\
\hline Published: 慧 February 11, 2021 & complications. Lichtenstein Tension free in repair of Open Inguinal Hernia remains the \\
\hline $\begin{array}{l}\text { Citation: Ahmed Abd El Aal Sultan. } \\
\text { Chemical fixation of mesh in repair of } \\
\text { inguinal hernia: long term follow up. } \\
\text { Biomed J Sci \& Tech Res 33(5)-2021. } \\
\text { BJSTR. MS.ID.005461. }\end{array}$ & $\begin{array}{l}\text { of recurrence. But fixation of mesh is still challenge in early and late post-operative period, } \\
\text { namely as regard pain which remain long lasting for a very long period. One of factors of } \\
\text { occurrence of pain possibly due to entrapment of nerve or nerve compression by sutures } \\
\text { during fixation of upper border of the mesh. Also, it may be due to periosteal reaction to } \\
\text { sutures fixed to the periosteum. Other explanations, due to excessive tension on muscles, } \\
\text { causing its ischemia. Hence many surgeons resort to alternative for mesh fixators, so one }\end{array}$ \\
\hline \multirow{3}{*}{$\begin{array}{l}\text { Keywords: Inguinal Hernia; Lichtenstein } \\
\text { Inguinal Hernioplasty; Cyanoacrylate; } \\
\text { Mesh Fixation; Postoperative Pain }\end{array}$} & of these alternatives was fixation by Cyanoacrylate. \\
\hline & $\begin{array}{l}\text { Aim: Aiming to study the effectiveness of Cyanoacrylate as fixator of mesh in repair of } \\
\text { inguinal hernia, as regard post-operative pain, hospital stay, time of mesh fixation, post- } \\
\text { operative pain, hospital stay, and recurrence of hernia. In long term follow up. }\end{array}$ \\
\hline & $\begin{array}{l}\text { Conclusion: The application of cyanoacrylate as fixator in Lichtenstein inguinal } \\
\text { hernia repair looks like a golden method for mesh fixation as it is safe, simple, less } \\
\text { operative time, less hospital stay with less complications as regard marked reduction in } \\
\text { postoperative pain in both short and long post-operative follow up. }\end{array}$ \\
\hline
\end{tabular}

\section{Introduction}

Inguinal hernia repair is one of the most common general surgical operations performed worldwide. More than a million inguinal hernia repairs are performed annually in the United States and Europe alone [1]. The Lichtenstein technique is the method of open repair most widely disseminated for treatment of inguinal hernia, with which the incidence of recurrence has been remarkably reduced, as we know this fact has been the most important quality index in inguinal hernia repair [2].

\section{Objectives}

More detailed information on cyanoacrylate in mesh fixation on lichtenstein tension free in repair of open inguinal hernia regard as postoperative pain, infection, recurrence, \& cost benefit. Long term Follow up.

\section{Patients and Methods}

The first study was conducted in Department of Surgery, ALHussein university Hospital, Al-Azhar University (Cairo) in the period from November 2017 to July 2018.3 followed by another study for long term follow up one year.

The Study at first was conducted on 10 patients, and was short term follow up but later on, the study increased to be long term follow up in period from November 2017 to November 2020. An informed consent was taken from all patients with a follow up period up to 3 year. The study was approved by the appropriate ethical authority of the hospital. Inclusion criteria: Patients are between 22 years and below 60 years, patients fit for surgery. 
Exclusion Criteria: Bilateral and/or recurrent hernia, femoral hernia, emergency presentation, unfit for surgery or suffering from associated acute or chronic illness.

\section{Technique}

Lichtenstein Tension free in repair of Open Inguinal Hernia but with Cyanoacrylate glue which was applied using specially syringe to cover the whole surface of the mesh using minimal amount of the glue $(0.5-2 \mathrm{ml})$; glue could be applied as drops at interrupted points over conjoint tendon, inguinal ligament and pubic tubercle. Lateral to the spermatic cord, the upper part of the mesh was flipped over the lower one and they were joined with one polypropylene stitch. The mesh was compressed against the inguinal floor for about 2 min.

\section{Statistical analysis}

The results were statistically analyzed. Data were fed to the computer and analyzed using IBM SPSS software package version 20.0.(Armonk, NY: IBM Corp). Qualitative data were described using number and percent. The Kolmogorov-Smirnov test was used to verify the normality of distribution, quantitative data were described using range (minimum and maximum), mean, standard deviation and median. Significance of the obtained results was judged at the 5\% level. The used tests were Chi-square test: For categorical variables, to compare between different groups. Monte Carlo correction: Correction for chi-square when more than $20 \%$ of the cells have expected countless than 5. F-test (ANOVA): For normally distributed quantitative variables, to compare between more than two groups, and Post Hoc test (Turkey) for pairwise comparisons. Kruskal Wallis test: For abnormally distributed quantitative variables, to compare between more than two studied groups.

\section{Results}

This study was a prospective, randomized. It was held in Department of Surgery, AL-Hussein university hospital, Al-Azhar University (Cairo) on 10 cases who were attendant to outpatient surgery clinic for elective repair of uncomplicated inguinal hernia. Using Prolene ${ }^{\circledR}$ mesh. Patients underwent inguinal hernioplasty with mesh fixation using (Cyanoacrylte) glue, their age ranged from $25-60$ years with a mean of $40.30 \pm 13.04$ and a median of 39.50. $70 \%$ had a right-side hernia while $30 \%$ had a left side one. $80 \%$ had an indirect inguinal hernia while $20 \%$ had a direct inguinal hernia. $10 \%$ had a history of other side hernia repair with Prolene ${ }^{\circledR}$ mesh. the time ranged from $2.0-6.0$ minutes with a mean of $4.0 \pm 1.33$ and a median of 4.0. The technical difficulties, was encountered in only $10 \%$, was obese and had disturbed anatomy. The overall operative time for this patient was 80 minutes while time needed for mesh fixation was 4 minutes. The surgeon recorded being unsatisfied in $10 \%$ earlier in the study when he was still not so familiar with the glue used for fixation which adheres tightly and rapidly to the underlying tissues making any trial for re-positioning was quite difficult.
In this case we used two ampoules of glue for fixation. The Cremasteric muscle was cut in $30 \%$ for better positioning of the mesh. The two nerves (Ilio-inguinal and genital branch of Genito-femoral nerve) were identified and preserved in $80 \%$ while accidental cutting of the Ilioinguinal nerve occurred in two patients $10 \%$. while clear identification of the two nerves failed in only $10 \%$. The post wall was weak and required a repair in $30 \%$. As regard to pain, evaluation of the post-operative pain was done using the VAS the pain score in the first post-operative day ranged from $2.0-4.0$ with a mean of $2.60 \pm 0.70$ and a median of 2.50 . The pain score in two weeks post-operative ranged from 1.0 - 3.0with a mean of $2.30 \pm 0.82$ and a median of 2.50 . The pain score in onemonth post-operative ranged from $0.0-4.0$ with a mean of 1.90 \pm 0.99 and a median of 2.0. The pain score in two months postoperative day ranged from $0.0-0.0$ with a mean of $0.0-0.0$ and a median of 0.0. After long term follow up, the results do not change as pain score ranged from $0.0-0.0$ with a mean of $0.0-0.0$ and a median of 0.0 . every year for 3 years and no recurrence occur. No additive analgesia needed in early post-operative period. $100 \%$ showed a gradual improvement of pain and became a pain free by the 2nd month post-operative. As regards to the hospital stay, ranged from $6.0-12.0$ hour with a mean of $9.30 \pm 2.45$ and a median of 10.0 .

\section{Discussion}

There has been increasing evidence in the literature over the last decade regarding the growing incidence of chronic groin pain. The exact cause for the pain is still unclear and various etiologies have been suggested, including the type of mesh, suture materials and tissue handling techniques [4]. The successful use of cyanoacrylate in the different surgical disciplines was the motive to perform such a prospective, randomized controlled study to compare the efficacy of mesh fixation by cyanoacrylate, sutureless and polypropylene suture for one day surgery of open inguinal hernia repair and all patients were re-examined using a standardized questionnaire at 1week, 30 days, 3 months and 6 months after surgery. Regarding the type of mesh fixation, recent literatures review to establish an evidence base for cyanoacrylate glue in mesh fixation and based on this evidence several studies have eliminated the use of sutures in mesh fixation to reduce chronic groin pain, this aims to avoid direct nerve irritation or nerve entrapment. On the other hand, mesh fixation with glue (tissue adhesive) seems an optimal choice to reduce postoperative pain. Accordingly, preliminary results published with different glues all showed promising results with reduced postoperative pain [5]. There are two studies reported their preliminary results of cyanoacrylate glue versus the use of sutureless method for mesh fixation in Lichtenstein repair; After 3 months, no recurrence was observed. Minor pain was observed after 3 weeks in 33\% patients in the sutureless group and in 18\% patients in the cyanoacrylate glue group, 3 months postoperatively $16 \%$ patients in the sutureless group and $5 \%$ patient in the cyanoacrylate glue group recorded minor pain. Local numbness 
was documented in $60 \%$ vs. $44 \%$ patients 3 weeks postoperatively and in $40 \%$ vs. $25 \%$ patients 3 months postoperatively in the sutureless group and cyanoacrylate group, respectively [6-8]. Shorter surgery time may be beneficial in terms of overall cost and reduced infection rate. In our series, there were no reported cases with mesh infection [3].

\section{Conclusion}

Finally, the application of cyanoacrylate as fixator in Lichtenstein inguinal hernia repair looks like a golden method for mesh fixation as it is safe, simple, less operative time, less hospital stays with less complications as regard marked reduction in postoperative pain in both short and long post-operative follow up. and can be used easily by any surgeon regardless the level of skills with no increase in the early or late recurrence rate. Of course, it will be of great value if larger, randomized, and controlled trial done to confirm the results of cyanoacrylate as fixator.

\section{References}

1. Rutkow IM (2003) Demographic and socioeconomic aspects of hernia repair in the United States in 2003. The Surgical clinics of North America 83(5): 1045-1051.

ISSN: 2574-1241

DOI: 10.26717/BJSTR.2021.33.005461

Ahmed Abd El Aal Sultan. Biomed J Sci \& Tech Res

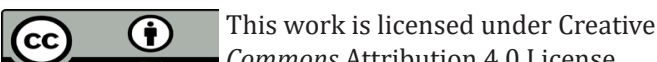

Submission Link: https://biomedres.us/submit-manuscript.php
2. Amid PK (2005) Groin Hernia repair: open techniques. World J Surg 29(8): 1046-1051.

3. Sultan AA EA, Ismail MSK, EL Anany MI (2018) Comparison between Cyanoacrylate, Sutureless and Polypropylene Sutures in Mesh Fixation on Lichtenstein Tension free in repair of Open Inguinal Hernia. The Egyptian Journal of Hospital Medicine 73(1): 5795-5806

4. Ladwa N, Sajid MS, Sains P, Baig MK (2013) Suture mesh fixation versus glue mesh fixation in open inguinal hernia repair: a systematic review and meta-analysis. International Journal of Surgery 11(2): pp. 128-135.

5. Hakeem A, Shanmugam V (2011) Inguinodynia following Lichtenstein tension-free hernia repair: A review. World journal of gastroenterology: WJG 17(14): 1791

6. Hoyuela C, Juvany M, Carvajal F, Veres A, Troyano D, et al. (2017) Randomized clinical trial of mesh fixation with glue or sutures for Lichtenstein hernia repair. British Journal of Surgery 104(6): pp. 688694.

7. Helbling C, Schlumpf R (2003) Sutureless Lichtenstein: First results of a prospective randomised clinical trial. Hernia 7(2): 80-84.

8. Kim-Fuchs C, Angst E, Vorburger S, Helbling C, Candinas D et al. (2012) Prospective randomized trial comparing sutured with sutureless mesh fixation for Lichtenstein hernia repair: long-term results. Hernia 16(1): pp. 21-27.

$\begin{array}{ll}\text { BIOMEDICAL } & \text { Assets of Publishing with us } \\ \text { RESEARCHES } & \text { - Global archiving of articles } \\ \text { - Immediate, unrestricted online access } & \text { - Rigorous Peer Review Process } \\ & \text { - Authors Retain Copyrights } \\ \end{array}$

